\title{
A Methodology for Developing Speed and Endurance of Teenagers
}

\author{
Velizar T. Pavlov ${ }^{1}$ and Veneta Simeonova ${ }^{2}$ \\ 1. University of Ruse, Studentska Str. 8, Ruse 7017, Bulgaria \\ 2. High School of Tourism, Lipnik Str. 4, Ruse 7000, Bulgaria
}

\begin{abstract}
The problem is a sustained decline in the average level of overall physical abilities of young people in Bulgaria. The aim of this work is to prepare a methodology for developing physical qualities: speed and endurance of teenagers and to implement it in lessons in Physical Education and Sport. Research methods include sports pedagogical experiment, testing and data analysis. Two groups were observed: a control and an experimental one. Our methodology is based on specialized athletics exercises. Their effectiveness is proved by depth statistical data analysis. The main result of the application of the methodology is significant positive changes in the speed and endurance of boys in the experimental group. Some personal comments about the experiment and conclusions are given.
\end{abstract}

Key words: Physical workability, speed, endurance, athletics, methods, data analysis.

\section{Introduction}

The physical development and activity of adolescents is the subject of various studies [1-3]. Physical workability is a set of potential for human motor activity with high efficiency, which is determined by diagnosis net of basic human physical qualities: speed, strength, jumping, endurance and flexibility [4]. The monitoring and the evaluation of the physical workability of students are carried out by the Bulgarian Ministry of Education and Science. A uniform set of motor tests is used for different stages and levels of training. In recent years, numerous studies [5-7] have shown that there is a sustained decline in the average level of the overall physical abilities of young people.

The aim of our research is to prepare an effective methodology for developing physical workability of teenagers and to implement it in lessons in Physical Education and Sport. In this paper, we present a part of this research which concerned development of the speed and endurance of teenagers.

Corresponding author: Velizar T. Pavlov, Ph.D., professor, research field: applied statistics. E-mail: vpavlov@uni-ruse.bg.

\section{Methods}

The study was conducted with students in the ninth grade of High school of Tourism in Ruse, Bulgaria. Two groups were observed: a control and an experimental one, each of which consisting of 34 boys (15-16 year old). The period of our pedagogical experiment is nine months-from October to June. Physical education and sport classes were conducted twice a week in both groups. Our methodology is applied in accordance with the standards for the educational content in the CG (control group). Furthermore, in each lesson, some complexes of athletic exercises to develop a natural quality were applied for about ten minutes in the EG (experimental group). Within the school year, the complexes were applied according to a prearranged plan.

To establish the level of development of motor skills of all participants in the experiment, a test battery consisting of eight indicators was used (Table 1). To assess the speed and the endurance of the participants in the CG and EG, a speed test (50 m sprint - $X 1$ ) as well as endurance test (600 m flat run - $X 2$ ) were used. 
Some information about the sets of athletic exercises, their dosage, organization and methodical instructions is presented in Table 2-for speed developing and Table 3-for endurance developing.

\section{Results and Discussion}

Two official tests in the CG and EG were conducted at the beginning of the period-October

Table 1 A test battery.

\begin{tabular}{llll}
\hline Indicator & Symbol & Measure & Measurements accuracy \\
\hline 50 m sprint & $X 1$ & $\mathrm{sec}$ & 0.01 \\
600 m flat run & $X 2$ & $\mathrm{sec}$ & 0.1 \\
Standing long jump & $X 3$ & $\mathrm{~cm}$ & 1.0 \\
Vertical jump & $X 4$ & $\mathrm{~cm}$ & 1.0 \\
Squatting and standing & $X 5$ & number & 1.0 \\
Throw 3 kg medicine ball with two hands above head & $X 6$ & $\mathrm{~cm}$ & 1.0 \\
Push-ups & $X 7$ & number & 1.0 \\
Depth of tilt & $X 8$ & $\mathrm{~cm}$ & 1.0 \\
\hline
\end{tabular}

Table 2 Exercises for speed developing.

\begin{tabular}{|c|c|c|}
\hline Content & Dosage & Organizational and methodical instructions \\
\hline $\begin{array}{l}\text { Movements with a maximum frequency (fine running, jumping } \\
\text { on the left or right, simulation movement of the hands, etc.). }\end{array}$ & $5 \times 6 \mathrm{sec}$ & $\begin{array}{l}\text { The frequency of movements at the end of the } \\
\text { exercise is not decreased. }\end{array}$ \\
\hline Some single movements (jump, movement of hands, etc.). & $\begin{array}{l}\text { Every ex. } \\
\times 5-6 \text { times }\end{array}$ & Movements are performed after beeping. \\
\hline Special running exercises. & $5 \times 2 \times 20 \mathrm{~m}$ & Apply the Competitive method. \\
\hline Accelerations. & $2-3 \times 60 \mathrm{~m}$ & Apply the Competitive method. \\
\hline $\begin{array}{l}\text { Starts from different starting positions - standing, sitting, lying, } \\
\text { squatting and knee support, etc. }\end{array}$ & $6 \times 15-20 \mathrm{~m}$ & Start after beeping. Competitive method. \\
\hline High, low and fly starts. & $6 \times 15-20 \mathrm{~m}$ & Apply the Competitive method. \\
\hline Running distances of 20 to $60 \mathrm{~m}$ from high start. & $2 \times 3 \times 40 \mathrm{~m}$ & $\begin{array}{l}\text { Intensity is } 90 \%-98 \% \text {. The break between distances } \\
\text { is } 1 \mathrm{~min} \text { and between series is } 3 \mathrm{~min} \text {. }\end{array}$ \\
\hline Running between marks. & $6 \times 20 \mathrm{~m}$ & $\begin{array}{l}\text { The aim is to find the optimum balance between } \\
\text { frequency and stride length. }\end{array}$ \\
\hline
\end{tabular}

Table 3 Exercises for endurance developing.

\begin{tabular}{|c|c|c|}
\hline Content & Dosage & Organizational and methodical instructions \\
\hline Long uniform running at low speed. & $10-12 \min$ & $\begin{array}{l}\text { Uniform running at low speed (heart rate } 120-160 \\
\text { beats/min). }\end{array}$ \\
\hline Long variable running without stopping to change the speed. & $10-12 \min$ & $\begin{array}{l}\text { Alternating long slow running and } 20 \mathrm{~m} \text { fast } \\
\text { running. }\end{array}$ \\
\hline Long uniform running at middle speed. & $2 \times 5 \min$ & $\begin{array}{l}\text { Uniform running at middle speed (heart more than } \\
160 \text { beats } / \mathrm{min} \text { ), the break is } 3-4 \text { min. }\end{array}$ \\
\hline Running at variable intensity. & $4 \times 100 \mathrm{~m}$ & $\begin{array}{l}\text { Alternating sections of } 20 \mathrm{~m} \text { speed run and } 20 \mathrm{~m} \\
\text { slow run. }\end{array}$ \\
\hline Running at intervals. & $\begin{array}{l}2 \text { series } \\
2-3 \times 50 \mathrm{~m}\end{array}$ & $\begin{array}{l}\text { The intensity is } 70 \%-80 \% \text {, the break is } 30 \mathrm{sec} \\
\text { between distances and } 3 \text { min between series. }\end{array}$ \\
\hline Repeat running. & $\begin{array}{l}3 \times 80 \mathrm{~m} \\
\text { or } 2 \times 120 \mathrm{~m}\end{array}$ & The intensity is $90 \%-95 \%$, the break is $3-4 \mathrm{~min}$. \\
\hline Relay games. & $3 \times 50 \mathrm{~m}$ & Apply the Competitive method. \\
\hline Moving games. & $10 \mathrm{~min}$ & Apply the Play method. \\
\hline Team play games. & $10-12 \min$ & Apply the Play method. \\
\hline
\end{tabular}

and at the end-June. In our analysis for the indicator number $J=1,2, \ldots, 8$ we denote: $X J_{(0)}$ and $X J_{(9)}$ the results obtained at the beginning and at the end (after 9 months) of the period. A verification by the Kolmogorov-Smirnov's criterion shows that for all of data in the CG and EG, it is true that $K-\operatorname{Sig}(2-$ tailed $)>\alpha=0.05$, where $\alpha$ is the risk of error (Table 4). Therefore, all of data are normally 
Table 4 The Kolmogorov-Smirnov 2-tailed test for normal distribution.

\begin{tabular}{lll}
\hline Indicators & \multicolumn{2}{l}{ Experimental group Control group } \\
\hline$X 1_{(0)}$ & 0.425 & 0.125 \\
$X 1_{(9)}$ & 0.415 & 0.178 \\
\hline$X 2_{(0)}$ & 0.994 & 0.989 \\
\hline $2_{(9)}$ & 0.944 & 0.772 \\
$X 3_{(0)}$ & 0.422 & 0.473 \\
$X 3_{(9)}$ & 0.981 & 0.671 \\
$X 4_{(0)}$ & 0.386 & 0.547 \\
$X 4_{(9)}$ & 0.495 & 0.384 \\
$X 5_{(0)}$ & 0.556 & 0.674 \\
$X 5_{(9)}$ & 0.434 & 0.853 \\
$X 6_{(0)}$ & 0.152 & 0.949 \\
$X 6_{(9)}$ & 0.730 & 0.553 \\
$X 7_{(0)}$ & 0.675 & 0.624 \\
$X 7_{(9)}$ & 0.169 & 0.565 \\
$X 8_{(0)}$ & 0.561 & 0.461 \\
$X 8_{(9)}$ & 0.469 & 0.669 \\
\hline
\end{tabular}

distributed.

This important result justifies applying the Student's criterion to prove the effectiveness of the methodology and the use of the Pearson's correlation coefficient.

Let us denote by $\overline{X J}_{(0)}$ and $\overline{X J}_{(9)}$-the averages of the results obtained at the beginning and at the end (after 9 months) of the period, respectively; $d=\overline{X J}_{(9)}-\overline{X J}_{(0)}$-growth in the above averages; $t$-empirical value of Student's t-criterion; 2-TailSig—significance level.

Table 5 presents the results of the speed data processing and the Student's $t$-test concerning changes in EG and CG. Five comparisons have been done to prove the effectiveness of the methodology.

A verification by the Student's criterion for dependent samples showed that at guaranteed probability close to $100 \%(P \approx 100 \%$, 2-TailSig $=$ $0.000)$. There is a statistically significant growth in the EG results (row 2-comparison 1). At the same time growth in CG (row 3-comparison 2) is not statistically significant (2-TailSig $=0.602) . \mathrm{A}$ verification by Student's criterion for two independent samples indicates that differences between EG and CG in the testing at the beginning are not statistically significant (2-TaiSig $=0.792)$, i.e. there is an "equal start" (column 2-comparison 3). Meanwhile, at the end of the experiment (column 3-comparison 4), differences between EG and CG are now statistically significant $(2-$ TaiSig $=0.038)$.

The growth of changes in the average value in EG is $-0.34 \mathrm{sec}$, while in the CG is $-0.06 \mathrm{sec}$. A verification by the Student's criterion shows that the difference between the two growths (column 4-comparison 5) is statistically significant (2-TaiSig $=0.000$ ).

The analysis of data (Table 5) proves that statistically significant changes occurred in the EG due to the applied methodology for speed developing.

In the same way, the effectiveness of the methodology for endurance developing was proved (Table 6).

The results obtained in EG at the end of the period were used for studying the influence of the speed $(X 1)$ on the endurance (X2). The Pearson's correlation coefficient $r=0.55$ is statistically significant $(\alpha<0.01)$. Hence, the coefficient of determination is $r^{2}=0.30$, which shows that about $30 \%$ of changes in the endurance are determined by the speed.

Table 5 The Student's t-test of changes in EG and CG for the indicator $50 \mathrm{~m}$ sprint $(X 1)$, in sec.

\begin{tabular}{llllll}
\hline Group & $\overline{X 1}_{(0)}$ & $\overline{X 1}_{(9)}$ & $d=\overline{X 1}_{(9)}-\overline{X 1}_{(0)}$ & $T$ & $2-$ Tail Sig \\
\hline Experimental & $7.85 \mathrm{sec}$ & $7.51 \mathrm{sec}$ & $-0.34 \mathrm{sec}$ & 3.609 & 0.000 \\
Control & $7.88 \mathrm{sec}$ & $7.82 \mathrm{sec}$ & $-0.06 \mathrm{sec}$ & 0.527 & 0.602 \\
Differences & $-0.03 \mathrm{sec}$ & $-0.31 \mathrm{sec}$ & $-0.28 \mathrm{sec}$ & & \\
$T$ & 0.265 & 2.118 & -7.715 & & \\
2-Tail Sig & 0.792 & 0.038 & 0.000 & & \\
\hline
\end{tabular}


Table 6 The Student's t-test of changes in EG and CG for the indicator $600 \mathbf{m}$ flat run $(X 2)$, in sec.

\begin{tabular}{llllll}
\hline Group & $\overline{X 2}_{(0)}$ & $\overline{X 2}_{(9)}$ & $d=\overline{X 2}_{(9)}-\overline{X 2}_{(0)}$ & $T$ & 2 -Tail Sig \\
\hline Experimental & $150.26 \mathrm{sec}$ & $140.67 \mathrm{sec}$ & $-9.59 \mathrm{sec}$ & 3.121 & 0.004 \\
Control & $150.70 \mathrm{sec}$ & $148.88 \mathrm{sec}$ & $-1.82 \mathrm{sec}$ & 0.775 & 0.444 \\
Differences & $0.44 \mathrm{sec}$ & $8.21 \mathrm{sec}$ & $-7.77 \mathrm{sec}$ & & \\
$T$ & 0.108 & 2.124 & -9.764 & & \\
2-Tail Sig & 0.915 & 0.037 & 0.000 & & \\
\hline
\end{tabular}

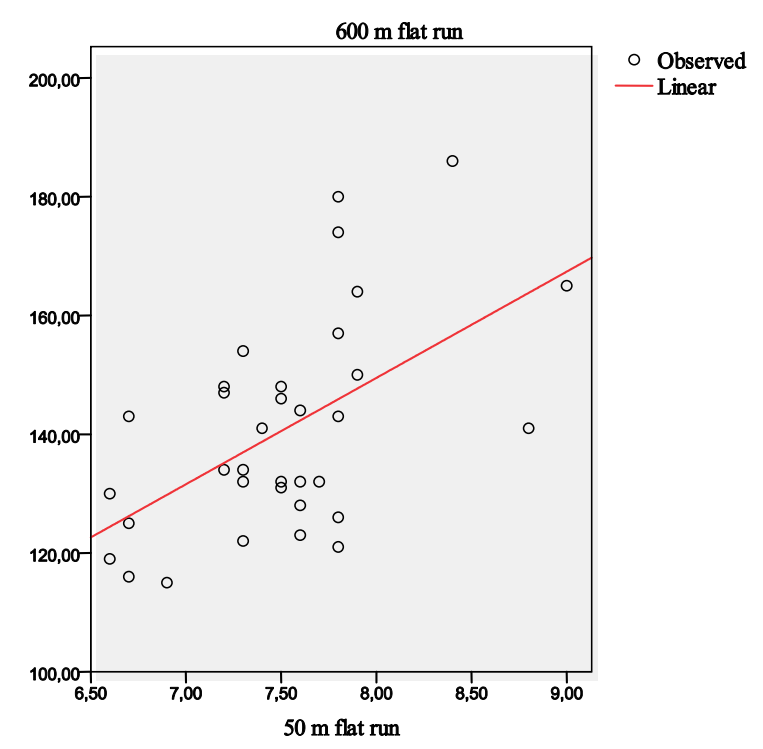

Fig. 1 Linear regression model of the relationship between $X 1$ (50 m sprint) and $X 2 \quad(600 \mathrm{~m}$ flat run).

The linear regression model describing the relationship between indicators $X 1$ (50 m sprint) and $X 2$ (600 m flat run) is $Y=17.9 x+6.26$ (Fig. 1). The model is adequate because significant level of the Fisher's criterion is Sign $F=0.0007<\alpha=0.01$. The variable factor regression coefficient is statistically significant $(\alpha<0.01)$ and shows that when the time of $50 \mathrm{~m}$ sprint decreases by $0.1 \mathrm{sec}$., then it is expected that the time of $600 \mathrm{~m}$ flat run to decrease by about 1-2 sec.

It is interesting to note that we obtain a similar result as Simeonova et al. [2]. In this work, our experiment was conducted with a combined group (n = 26) of 16 year-old boys from several high schools. All of these boys at their wish were included in the group. So, in this case, there are some differences in our methodology, of course. But it is important to note that in the end of the period (after 9 months again) there is a similar significant middle correlation $r=0.53$ between the same indicators $50 \mathrm{~m}$ sprint and $600 \mathrm{~m}$ flat run. Here the linear adequate regression model is $Y=9.2 x+66.4$, i.e. when the time of $50 \mathrm{~m}$ sprint decreases by $0.1 \mathrm{sec}$, then it is expected that the time of $600 \mathrm{~m}$ flat run to decrease by about 1 sec.

Finally, as a result of our personal impressions of the experiment, we can summarize that the boys participate in the test $50 \mathrm{~m}$ sprint with a greater desire, fatigue is not large, but the results are improving more slowly. At the same time, in the test $600 \mathrm{~m}$ flat run the fatigue is larger and the results are improving faster. The exercises for speed lead to improved endurance.

\section{Conclusions}

The experiment and the analysis of the results lead to the following conclusions:

(1) A proper methodology for developing speed and endurance of teenagers was prepared and implemented in lessons in Physical Education and Sport in secondary school;

(2) The effectiveness of the prepared methodology was proved and the main result of their application is significant positive changes in the speed and endurance of teenagers;

(3) A middle significant correlation between the speed and endurance was established as about $30 \%$ of changes in the endurance are determined by the speed;

(4) An adequate regression model of established dependence was composed and It shows that when the time of $50 \mathrm{~m}$ sprint decreases by $0.1 \mathrm{sec}$., then it is expected that the time of $600 \mathrm{~m}$ flat run to decrease by about 1-2 sec. The similar result is obtained in as Simeonova et al. [2];

(5) The presented methodology and data analysis of 
its application could be successfully used by teachers in lessons in Physical Education and Sport for students in secondary school.

\section{References}

[1] Galov, M. 1996. "On the Problem of Monitoring and Evaluating the Physical Activity of Adolescent.” Sport \& Science 3: 124-30. (in Bulgarian)

[2] Simeonova, V. and Pavlov, V. 2012. "Development of Physical Workability of 16-year Old Boys Practicing Athletics in Out-of-class Time.” Sport \& Science 3: 152-60.(in Bulgarian)

[3] Yukako, L., Miyazaki, M., and Uchida, S. 2010. "Developmental Changes in Cognitive Reaction Time of
Students Aged 14-16 Years.” European Journal of Sport Science 3: 151-8.

[4] Slanchev, P. 1992. On the Physical Development and Physical Workability of the Population in Bulgaria. Sofia: National Sport Academy. (in Bulgarian)

[5] Amstrong, N. 1997. "Young People and Physical Activity”. Oxford University Press 1 (1): 369-78.

[6] The European Health Report 2005. "Public Health Action for Healthier Children and Populations.” World Health Organization. Accessed September 7, 2006. http://www.euro.who.int/_data/assets/pdf_file/0004/824 35/E87325.pdf

[7] Yaneva, R. 2010. "Unfavorable Consequences Due to Low Physical Activity and Ways for Their Prevention.” Sport \& Science 4: 172-7. (in Bulgarian) 